\title{
Dossier
}





\section{Estrategias y redes de negociación del juez diputado de Trujillo, don Tiburcio de Urquiaga y Aguirre, 1780-1820}

\section{Strategies and negotiation networks of the deputy judge of Trujillo, don Tiburcio de Urquiaga y Aguirre, 1780-1820}

Frank Manuel Díaz Pretel ${ }^{1}$

Universidad Nacional de Trujillo

\section{Resumen}

Descripción de la situación del comercio y los comerciantes de la ciudad de Trujillo, Perú, a través del estudio de un caso representativo, el juez diputado de comercio de dicha ciudad entre 1780 a 1820 . Se estudia sus inicios en la actividad comercial, la conformación de su red y la creación de su casa comercial, el espacio en el que se desenvolvió y en el que aplicó una serie de estrategias que lo convirtieron en la autoridad más representativa del gremio de comerciantes. Abarca también las modalidades de negociación (comercio intercolonial y a distancia), los productos despachados y la rentabilidad de la actividad que desplegó. El objetivo es mostrar las caracte-

1 Máster en Historia de América Latina. Mundos Indígenas (Universidad Pablo de Olavide de Sevilla). Contacto: frank_07_09@hotmail.com 
rísticas peculiares del mercado trujillano y sus agentes en las postrimerías del periodo virreinal.

Palabras clave: Intendencia de Trujillo (Perú), Virreinato, libre comercio, comerciantes, negociaciones comerciales, redes sociales

\section{Abstract}

Description of the situation of commerce and traders in the city of Trujillo, Peru, based on the study of a representative case, the deputy judge of commerce in that city between 1780 and 1820. It covers his beginnings in the trade activity, the creation of his network and commercial company, and the space in which he worked and applied a series of strategies that turned him into the most representative authority of the merchant guild. It also includes the modalities of negotiation (intercolonial and distance commerce), the products dispatched and the profitability of the activity that was deployed. The aim is to show the peculiar characteristics of the Trujillo market and its agents at the end of the viceroyalty period.

Key words: Intendencia de Trujillo (Peru), Viceroyalty, free trade, traders, trade negotiations, social networks

\section{Introducción}

El periodo colonial tardío representó la recuperación imperial española durante el gobierno de los borbones, que en el Perú se caracterizó por el fortalecimiento de las defensas imperiales, la racionalización de la administración provincial, las mejoras y expansión de la recaudación de rentas, la libe- 
ralización del comercio y la introducción de reformas para centralizar la autoridad imperial en manos de una monarquía que confiaba en sí misma y planteaba convertir a América en una fuente de fortaleza económica y estratégica para la metrópoli (Fisher, 2000, p. 67).

Fue a mediados del siglo XVIII (1759-1788), con la política implementada por Carlos III y sus ministros, cuando se aplicó el Reglamento para el Libre Comercio en 1778 y se impusieron modificaciones en el ámbito mercantil con la intención de reducir el contrabando y aumentar el comercio. Con este objetivo, se impuso un tipo de arancel cero para algunos productos españoles y americanos. Sobre todo, se buscó sanear la economía, hacer más eficiente la recaudación y llevar un mayor control administrativo (Mazzeo, 2012, p. 63).

En el caso limeño, hubo un incremento comercial de $400 \%$ entre 1778 y 1796 y aumento de la exportación de productos no tradicionales, como el cobre y la cascarilla, que benefició a los comerciantes. Pero la exportación de oro y plata bajó en relación con los 10 años de la aplicación del reglamento, lo que ocasionó que los comerciantes no pudieran recuperar el dinero prestado, dado que la redención de sus empréstitos se realizaba mediante el aumento de impuestos, por ello, debieron buscar otras alternativas de solución para superar esa etapa (Mazzeo, 2012, pp. 73-76).

En el caso trujillano, se corrobora la trascendencia del referido reglamento, pues quebró el sistema tradicional de monopolio y dio origen a una nueva etapa. Aunque en un primer momento los grandes exportadores criollos establecidos en la ciudad de Trujillo gozaron de prerrogativas, pronto debieron ceder ante el ingreso de un gran número de comerciantes me- 
nores originarios de la península, que no obstante el inminente enfrentamiento de intereses con los firmemente establecidos, gozaban de una serie de ventajas, como el hecho de prepararse antes de emprender el riesgoso viaje transoceánico, contaban con la protección y promoción estatal, tenían importantes contactos en las principales ciudades de la metrópoli y estaban influenciados por el movimiento de la ilustración, que desplegó un comercio profesionalizado y estimuló la agricultura de exportación. Por ello, la estrategia empleada por ambos grupos inicialmente enfrentados fue la concertación de alianzas, generalmente mediante el matrimonio.

\section{El comerciante y la función de la familia}

Tiburcio Pascual de Urquiaga y Aguirre nació en la anteiglesia de Santa María de Mañaria, en Duranguesado, Vizcaya, el 15 de abril de 1752 y fue miembro de una familia de hidalgos con importantes conexiones en Valdespeña de la Mancha y Sevilla. Debió educarse en una academia militar, pues a los 17 años ya era capitán de infantería y fue destacado a Trujillo, Perú, donde una vez establecido, empleó una serie de mecanismos para acceder a los estamentos más elevados del medio. Así, en la octava década del siglo dieciocho concretizó los dos procedimientos fundamentales: se emparentó por medio del matrimonio con familias criollas establecidas con anterioridad e ingresó al cabildo local con el cargo de regidor perpetuo. ${ }^{2}$

Las vinculaciones consanguíneas fueron indispensables en el gremio de comerciantes y funcionaban como una especie de

2 Archivo Histórico Eclesiástico de Biskaia [en adelante AHEB], Fondos Parroquiales, libro de registros originales de bautismos (1656-1755), $298 \mathrm{r}^{\circ}$. 
entretejido que sustentaba su poder. Vinculados por lazos familiares, se ayudaban y protegían mutuamente debido a las condiciones riesgosas del comercio de ultramar. Las estirpes, como la que nos ocupa, funcionaban con una gran cohesión y eran verdaderas empresas familiares que prosperaron en Europa y América, mantenían una unidad primaria de lealtad e identidad, al mismo tiempo que proporcionaron asociados de confianza y vías de capital no siempre disponibles (Mazzeo, 1994, pp. 75, 77).

Una interesante tipología para las trayectorias de los comerciantes limeños en función del dinamismo, fortuna y vinculaciones establece rangos denominados "círculos concéntricos" (Rizo-Patrón, 2001, pp. 17-18). Aunque para el caso trujillano dieciochesco apenas se han iniciado estudios de corte biográfico, salvando espacios y haciendo una primera comparación, bien podría Tiburcio de Urquiaga compatibilizar con el círculo intermedio, pues fue un comerciante opulento con una patente fortuna diversificada en su casa comercial, crédito, conocidas haciendas y obrajes en la sierra inmediata, como Llaray y Uningambal, una chacra en la costa y propiedades urbanas.

El único factor que no alcanzó fue exhibir hábitos de una orden militar, en cambio, obtuvo carta de filiación de hidalguía y vizcainía en 1786, lo que certifica su condición de nobleza. Las evidencias parecen demostrar que estos distintivos resultaron secundarios frente al despliegue de energía e interés en sus actividades mercantiles, que en cierta manera estipulaban las Juntas de la Real Sociedad Bascongada de Los Amigos del País a sus ciudadanos. Tuvo además buenas conexiones matrimoniales y familiares; en primeras nupcias se casó con Petronila de Anachuri y Rucoba, descendiente de una familia 
criolla establecida en Trujillo, que alcanzó el éxito combinando la comercialización de efectos importados, textiles de la tierra y su vinculación con los Rucoba, importantes comerciantes cargadores del virreinato peruano que contaban con embarcación propia.

En segundas nupcias, se casó con Josefa Lynch, hija de Diego Lynch Brown, uno de los vecinos más importantes de la ciudad y un comerciante con fuerte inversión en el mineral de Hualgayoc, además de contar con una red consanguínea en las plazas más importantes de aquel entonces: Lima, Río de la Plata, Sevilla, Cádiz e Irlanda. En su etapa de liderazgo mercantil, Tiburcio de Urquiaga ocupó el cargo más pugnado por los vecinos del comercio: el de juez diputado de comercio, una clara demostración de sus dotes y profesionalismo en el ámbito comercial.

Al priorizar su actividad comercial, los parientes políticos se constituyeron en miembros fundamentales de la red. Estos fueron los parientes colaterales de Petronila de Anachuri, a saber, su prima hermana Mónica de Herrera y Rucoba, dueña de la hacienda San Francisco de Paula, en el valle de Chicama, y desposada con Santos Arangoitya, vecino del comercio de Trujillo. Otros relacionados de Urquiaga por la línea de su esposa fueron sus primos, los Algarate y Rucoba,

22 miembros del alto comercio de la ciudad; sus primos segundos, los hermanos Alvirena y García Benites, hacendados en Jocos y Joquillos, avecindados en Lima y con importantes contactos en Cajamarca; su primo el doctor Nicolás Cortés y Rucoba por cuya línea estaba vinculado con José Antonio de Lavalle y Cortés, primer conde de premio real y uno de los mayores comerciantes trujillanos establecidos en la capital. Miembros de la red familiar mucho más cercanos fueron su 
concuñado Joaquín de Rosillo y Velarde casado con Feliciana de Anachuri y Rucoba, con quienes mantuvo relaciones fluidas y compartían parte de los bienes e intereses comerciales heredados del finado Justo de Anachuri.

Hacia 1785, los intereses de Tiburcio de Urquiaga y los de Diego Lynch estuvieron íntimamente relacionados hasta el punto de efectuarse un pacto de familias mediante el conocido matrimonio con su hija Josefa. El irlandés Lynch tenía un mercado directo en Hualgayoc, donde también tuvo tiendas, especialmente en los poblados cerca del cerro rico y en el mismo campamento minero, pues los trabajadores de las minas -grupo conocido por sus altos salarios y su tendencia al despilfarro- constituían un mercado lucrativo para los artículos de lujo importados. Los artículos de la compañía Lynch y Urquiaga se incluían en este circuito (Brading, 1971, p. 139).

Las modalidades de comercialización entre ambos fueron diversas: poderes, préstamos y escrituras de obligación; estas últimas funcionaban como un pagaré. Por ejemplo, el 23 de enero de 1792 Tiburcio se obligó pagar a Diego Lynch la cantidad de 8,000 pesos con un interés del $6 \%$ anual; esta suma fue cancelada en su integridad al poco tiempo, lo que evidencia dinamismo en la actividad lucrativa y alta rentabilidad del mercado de Hualgayoc desde su descubrimiento en $1771 .{ }^{3}$

El aislamiento del asiento minero respecto a otros poblados y la gran distancia que había hasta la Caja Real de Trujillo que

3 Archivo Regional de La Libertad [en adelante ARLL] Protocolo, Concha y Mansubillaga, leg. 297 (1791-1792), e. 42, ff. 8-8v.; Protocolo, Vega Bazán, leg. 398 (1792-1793), e. 276, ff. 1156-1157v. 
los gobernaba ocasionaron graves problemas a los mineros de Hualgayoc. El azogue y otros insumos esenciales debían ser transportados desde esta capital, lo cual se prestaba a la especulación y acaparamiento por parte de algunos vecinos como Diego Lynch, según se constata en sus ingentes adquisiciones entre 1773 a 1782. Por ello, los mineros locales solicitaron reiteradamente el traslado de la Caja Real a Hualgayoc, de donde provenían los mayores ingresos para el fisco, pero su pedido no llegó a ser atendido. Los mineros se quejaron por el alto precio del azogue (150 pesos el quintal) y la escasez de mano de obra, por lo que se limitaron a beneficiar únicamente minerales de ley de doce marcos (Contreras, 1999, pp. 20-21).

Diego Lynch fue también "un rescatador de plata", comerciante que habilitaba a los mineros proporcionándoles préstamos en especies y géneros, y obligándolos a pagar en plata piña con un valor menor al establecido por el mercado, para enviarla luego a las Reales Cajas de Lima; de esta manera, fueron los que controlaron el mineral. Sus buenas relaciones con los mineros y azogueros de Hualgayoc resultaron fundamentales, uno de ellos fue José Monzón de Aguirre, quien realizaba cobranzas en la jurisdicción de Cajamarca y de manera recíproca depositó su confianza en Diego Lynch para encargarle gestiones en Trujillo. ${ }^{4}$

4 ARLL Protocolo, Vega Bazán, leg. 404 (1785-1806), ff. 11. 


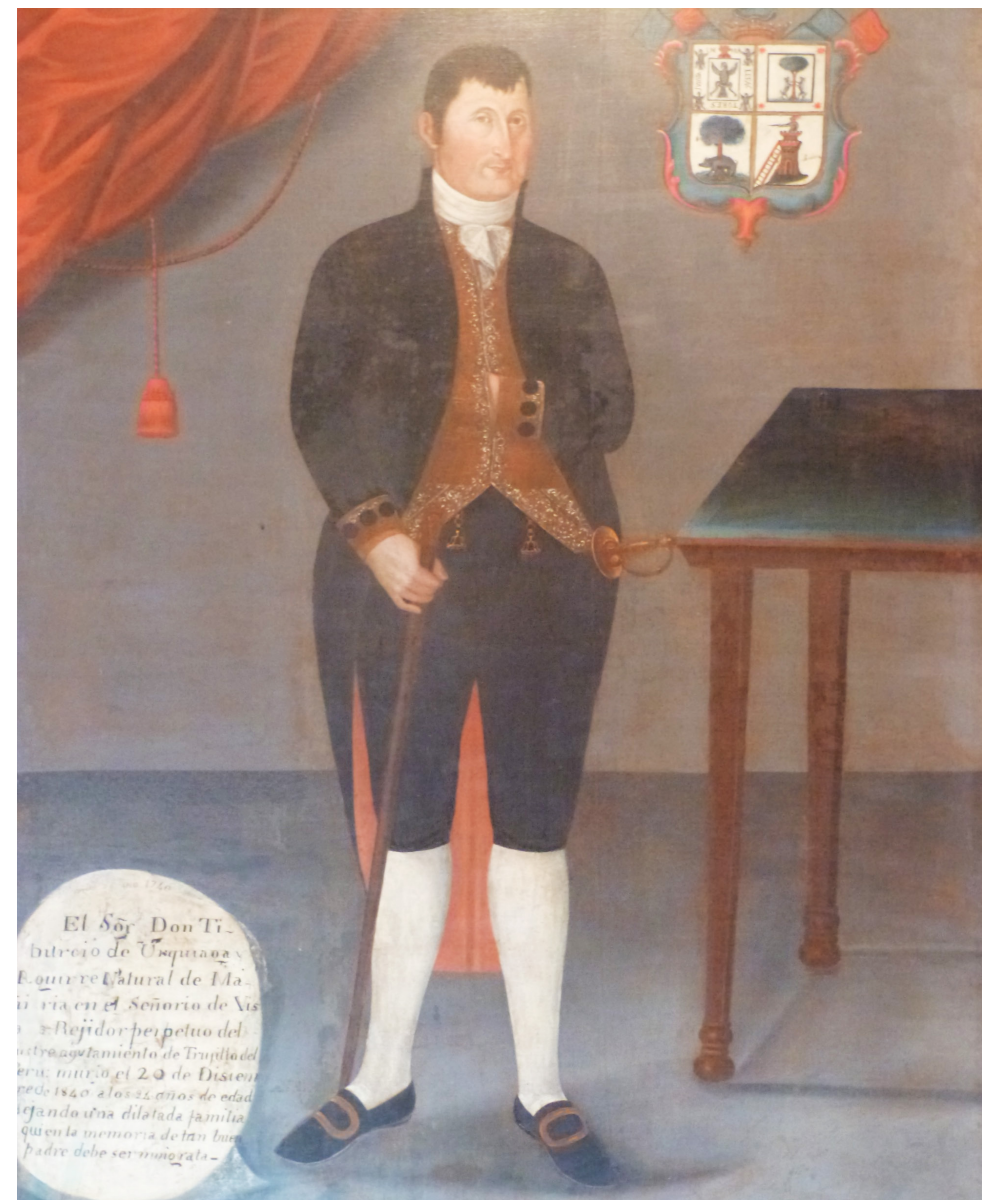

Figura 1. Lienzo del regidor perpetuo don Tiburcio de Urquiaga y Aguirre, que se encuentra en el museo del Banco Central de Reserva de Trujillo

\section{La consolidación de la red familiar: Los miembros de la segunda generación}

Brading apunta que ni en la península ni en el Nuevo Mundo los comerciantes españoles fomentaron a sus hijos conti- 
nuar sus actividades, por el contrario, si tenían éxito, querían darles carrera y educarlos para las profesiones y el servicio del gobierno, es decir, "para hacerlos señores" (1971, p. 147). En el caso peruano, también se alentaba a los hijos a seguir la carrera profesional, eclesiástica o militar, pero siempre un integrante de la familia continuaba las actividades del padre y sus negocios, según ha confirmado Mazzeo (1994, p. 68). A propósito, los hijos de Tiburcio de Urquiaga representan un caso exclusivo de Trujillo.

Del primer matrimonio, Fernando estudió leyes, Pedro Antonio y José continuaron la administración de las haciendas familiares, Manuel siguió la carrera comercial, mientras que Petronila se casó con su primo hermano, lo que fortaleció la casa comercial por relaciones de familia. Del segundo casamiento, Antonio fue un activo miembro de la firma familiar y Feliciana entregó su mano a un importante comerciante bonaerense, Juan Crisóstomo José de Sarratea y Altolaguirre, lo que denota una marcada tendencia a fortalecer sus redes mercantiles en un espacio de interacción amplio.

Para un comerciante próspero, era necesario conservar la casa comercial familiar, porque la suspensión súbita de las operaciones mercantiles o una rápida subasta de las existencias generalmente comportaba pérdidas económicas. Por ello, en

26 América hispana, el patrón general de los comerciantes era casar a sus hijas con sus ayudantes, a quienes empleaban para hacerse cargo de sus establecimientos. Estos parientes vivían en casa de su patrón y en muchos casos eran sus sobrinos, a quienes se les daba preparación, se les hacía socios y luego se casaban con una de sus hijas, así, muchas casas mercantiles sobrevivieron a la muerte de su fundador (Brading, 1971). 
Esta estrategia coincide perfectamente con este estudio de caso, pues para expandir sus redes comerciales no solo trajo a un sobrino, sino a dos, ambos jóvenes hijos de sus hermanos. El primero, Juan Antonio de Ochayta y Urquiaga, se casó con su prima Petronila de Urquiaga y Anachuri. Mientras que Francisco de Paula de Urquiaga y Ballesteros se vinculó con María Petronila de Larrea y Cárdenas, hija de un importante clan de comerciantes de Trujillo y hacendados de San Juan Bautista de Gasñape y de San José de Buenavista, en el valle de Chicama.

Francisco de Paula fue enviado a Trujillo a pedido expreso de Tiburcio, quien a fines de 1795 escribió a su hermano Juan Antonio para solicitarle que le "remita a uno de sus hijos para cuidar de su educación y fortuna”. El mozo, soltero, tenía 21 años cuando fue elegido para tal empresa y el 12 de enero de 1796 se embarcó en la fragata San Pedro, alias "La Reina", amarrada en el puerto de Cádiz para partir hacia el Callao. ${ }^{5}$ A su llegada, repitió de manera optimizada los escalones por los que atravesaban los inmigrantes: actividades comerciales bajo la tutela de su tío, ejercicios políticos y vinculación matrimonial ventajosa. Por si fuera poco y a pedido de su pariente, en 1802 se celebró un cabildo extraordinario para recibirlo como síndico procurador general de la ciudad. ${ }^{6}$

Petronila de Urquiaga y Anachuri se casó con su primo hermano Juan Antonio de Ochayta y Urquiaga el 20 de junio 1798, luego de cumplir las diligencias prevenidas por el Concilio de Trento y la respectiva dispensa de impedimento de segundo

5 Archivo General de Indias [en adelante AGI], Juzgado de Arribadas y Alzadas de Cádiz, leg. 518, número 176.

6 ARLL Cabildo, Actas de Sesiones, libro 17 (1794-1802), ff. 281. 
grado de consanguinidad que mediaba entre ambos. ${ }^{7}$ Siete días más tarde se elevó la escritura de carta dotal por la cantidad de 10,019 pesos 4 reales, y 5,000 pesos de arras "atendiendo a la honestidad, virtud y loables prendas de que está naturalmente exonerada”. Se agregaron a su dote 500 pesos, como concepto de una obra pía cuyos réditos anuales servían para dotar a "dos niñas doncellas de calidad en sangre". ${ }^{8}$

Juan Antonio llegó a Trujillo antes de 1797 y una vez asentado combinó sus actividades militares con el comercio de importación y exportación en asociación con su tío y suegro, quien más adelante le confirió amplias potestades y acciones en su casa comercial, vinculándola más adelante y por medio del matrimonio de sus hijas con los Calonge y Ortiz de Gálvez, comerciantes procedentes de Panamá. Los Ochayta y Urquiaga amasaron una enorme fortuna a partir del comercio, además de numerosos bienes raíces, como tiendas de comercio y una ostentosa residencia ubicada en la plaza de armas, colindante con el cabildo, una casa por medio.?

\section{El juez diputado de comercio: El liderazgo comercial de un comerciante vasco}

Los consulados de comercio fueron instituciones privadas gremiales, que tenían como principal objetivo solucionar los

28 pleitos mercantiles con mayor rapidez que los llevados en la

7 Archivo El Sagrario de Trujillo [en adelante AEST], Matrimonio de españoles, lib. 1790-1826, ff. 55v.

8 ARLL Protocolo, Concha y Mansubillaga, leg. 305 (1800), e. 47, ff. 74. ARLL Protocolo, Vega Bazán, leg. 401 (1800-1801), e. 18, ff. 24-25.

9 ARLL Protocolo, Concha y Mansubillaga, leg. 307 (1802), e. 140, ff. 376-385v. Vega Cárdenas, 2009. 
Real Audiencia. Otras de sus funciones fueron la recaudación de los derechos reales, especialmente el almorifazgo, la alcabala y la avería, así como la obtención de dinero en efectivo para hacer frente a las cuestiones bélicas, convirtiéndose en los agentes financieros más importantes de la Corona (Mazzeo 2012, pp. 31-32). En estos consulados de comercio, en el último cuarto del periodo virreinal, existían once diputaciones a cargo de representantes que tenían el título de jueces diputados de comercio, cargo que ostentaban los comerciantes más importantes. Los fallos de los diputados de comercio en provincia (primera instancia) podían ser impugnados y llevados al tribunal en la capital (Aldana, 1999, pp. 156-158).

En Trujillo, el gremio mercantil local tuvo un proceso de crecimiento productivo desde mediados del siglo y con mayor fuerza a partir de 1771, al convertirse en un eje articulador del mercado interno, que abastecías de insumos a las regiones mineras circundantes y también vinculó dicho mercado con el comercio de ultramar al recibir importantes cantidades de productos importados desde la liberación del puerto de Huanchaco en 1796. Uno de los mercaderes más prominentes de la ciudad fue Tiburcio de Urquiaga, quien ostentó el cargo durante 23 ańos (1797-1820).

La creación de nuevos consulados y legislaciones al respecto plantearon que el comercio no era su único objetivo, sino que se pretendía fomentar también la industria y la agricultura, aunque esto fracasó en algunas economías, como la sevillana. No pasó lo mismo en los erigidos en América, el consulado de Valparaíso promovió el cultivo del lino, la fabricación de telas y la creación de una academia de enseñanza técnica. En Veracruz, se buscó la introducción de colonos para el desarrollo de la cría del gusano de seda (Mazzeo, 1971, pp. 86-87). 
En Trujillo, Tiburcio de Urquiaga, como representante del Tribunal del Consulado, incentivó la producción de tejidos de calidad superior (tocuyo y bayetón), que superó a la manufactura de Cuenca, también emprendió campañas de capacitación de los indios hilanderos para que aprendieran a maniobrar el torno y lograran una hechura más fina que con el huso, que era la práctica común. También propició el sembrado de alcaparrosa y alumbre en vetas considerables de los territorios yungas de Uningambal. ${ }^{10}$ En este sentido, los nuevos consulados fueron producto de una nueva generación que siguió una tendencia enmarcada dentro del pensamiento de la Ilustración (Mazzeo, 1971).

Por Real Orden expedida en Zaragoza el 25 de agosto de 1802 se solicitó que todos los consulados presentasen informes de sus respectivas jurisdicciones. El 9 de abril el juez diputado de comercio de Trujillo presentó un impecable informe titulado Razón circunstanciada que don Tiburcio de Urquiaga y Aguirre diputado del comercio de la ciudad de Trujillo produce al consulado de Lima, con relación a los ramos de aquella provincia. Para su elaboración, consideró necesario "puntualizar con una veracidad algunas cosas que fueran precisas patentizarlas personalmente para proceder con acierto a este superior e importante cargo que se puso a mi cuidado", lo que demuestra el profesionalismo de este comerciante en

30 el análisis económico de su jurisdicción, que comprendió en la costa desde el pueblo de Virú por el sur al de Paiján por el norte, y en la sierra, la provincia de Huamachuco. ${ }^{11}$

10 Archivo General de la Nación [en adelante AGN] Tribunal del Consulado, Gobierno Político Administrativo, caja 6, doc. 125.

11 AGN Tribunal del Consulado, Gobierno Político Administrativo, caja 6, doc. 125 . 


\section{El espacio mercantil y las modalidades de comercialización}

El grupo de jóvenes que se trasladó en la oleada migratoria del siglo XVIII incluía una gama de lo más diversa, entre quienes también se distinguía a los promovidos por la Corona, como fue el caso de los burócratas y militares. El capitán Urquiaga fue destacado como oficial del ejército real a Trujillo, además, venía con miras de buscar su desarrollo personal y expandir sus redes. El espacio en el que se asentó estaba plenamente consolidado, por lo que resultaba imprescindible su vinculación matrimonial con una familia criolla que aportara, entre otros beneficios, una red de colaterales. La inmigración de por sí no aseguraba nada, tenía que atravesar una serie de escalones en una sociedad de antiguo régimen que le permitiese -mediante la actuación de poderosos parientes o allegados- posicionarse en el cerrado círculo de nobles y gremio de comerciantes.

El personaje llegó a Trujillo en 1771 y estuvo ocupado en los procedimientos antes referidos paralelo al desempeño de sus actividades militares, lo que duró casi una década. Recién en 1780, cuando pasó de "residente" a "vecino" de la ciudad de Trujillo, contrajo matrimonio, y coincidentemente por esas fechas las escrituras de protocolos públicos comenzaron a registrar sus negociaciones en giro. Un comerciante trujillano no solo tenía que estructurar una red, sino también gozar de buena reputación y crédito. En el mundo comercial, los miembros de una misma familia jugaban un papel transcendental como asociados y corresponsales. Había dos razones que animaban a los comerciantes a asociarse con sus parientes como agentes en ultramar, estaban más a mano que nadie y por lo general nadie inspiraba más confianza que ellos, 
motivo por el cual Tiburcio de Urquiaga hizo venir a sus dos sobrinos, además de integrar a todos sus hijos en la empresa familiar. Sin embargo, no siempre fue posible tener un pariente en cada uno de los lugares con los que se comerciaba. Por eso, los comerciantes que participaban en el tráfico internacional debían contar con una extensa red de contactos como agentes, factores y empleados (Lamikiz, 2008, p. 3).

Los comerciantes adquirían prestigio mediante dos canales: el secular y el eclesiástico. Ser elegido por instituciones para confiarle sus capitales o actuar como mayordomos de órdenes religiosas, les otorgaba crédito y estatus social (Mazzeo, 1994, p. 69). En el primer canal, desempeñó cargos de confianza de vecinos de la ciudad que pronto hablarían de su "arreglada conducta”, así, fue albacea dativo de María Francisca Bocanegra, vecina de Piura, apoderado del conde de San Xavier y del conde de Valdemar de Bracamonte, representante de su comadre María Trinidad de Rucoba, fiador de Pedro Calderón de la Barca en su empleo de ministro tesorero en las Reales Cajas, además de anfitrión de personalidades de importancia, como acaeció en mayo de 1811, cuando hospedó en su casa a Antonio Pareja, brigadier de la Real Armada y caballero de la orden de Santiago, que viajaba con rumbo a Lima. ${ }^{12}$

Sus iniciales vinculaciones en Lima resultaron ser tan selectas

32 como las que obtuvo en el norte del virreinato, ya en agosto de 1785 fue designado como apoderado para las ventas de esclavos de Antonio de Elizalde, caballero de Santiago y el

12 ARLL Protocolo, Vega Bazán, leg. 396 (1788-1789), e. 171, ff. 505v.508v. ARLL Intendencia, causa ordinaria, leg. 341, exp. 1020. ARLL Protocolo, Concha y Mansubillaga, leg. 323 (1811-1819), e. 108, ff. $182 \mathrm{v} .-184 \mathrm{v}$. 
cónsul más antiguo del Tribunal del Consulado. ${ }^{13}$ En setiembre de 1786, se encontraba realizando el mismo giro, esta vez como apoderado del comerciante limeño Juan José de Larramendi. ${ }^{14}$ En marzo de 1789 se desempeñó como apoderado general de Domingo de Larrea y Ames, vecino de Lima que le encomendó la prosecución de ciertos autos en la intendencia de Trujillo. ${ }^{15}$

Por otro lado, su prestigio a nivel secular fue catapultado por la confianza que le depositó el sector eclesiástico; llegó a ser síndico del convento de San Francisco en 1790 y recibió la confianza que le confirieron unos curas doctrineros de diferentes locaciones de la intendencia para distintos motivos, como fianza en el remate de diezmos, cobranza de sus sínodos, albaceazgo e inventario de bienes (véase el cuadro 1), como el que efectuó con la mayor escrupulosidad del $10 \mathrm{al}$ 11 de enero de 1786 tras la muerte de Bernabé Caballero. Estas personas del clero gozaban de rentas y ahorros, que podían ser útiles a un comerciante en caso de requerir un préstamo, como el que el vasco otorgó al doctor José Miguel Espinoza, cura de la doctrina de Virú, el 12 de diciembre de 1799. ${ }^{16}$ Gozaban también de importantes vinculaciones en sus lugares de origen como fue el caso de los presbíteros del Castillo (emparentados con los Velásquez Tineo), miembros de una de las familias más importantes de la región piurana (Hernández, 2008, pp. 177-183).

13 ARLL Protocolo, Vega Bazán, leg. 394 (1784-1786), e. 97, ff. 272-276v. 14 ARLL Protocolo, Vega Bazán, leg. 394 (1784-1786), e. 20, ff. 80v.-84v. 15 ARLL Protocolo, Vega Bazán, leg. 396 (1788-1789), e. 152, ff. 462v.-463. 16 ARLL Protocolo, Vega Bazán, leg. 400 (1798-1799), e. 141, ff. 357-357v. 


\section{Cuadro 1. Relación de Tiburcio de Urquiaga con ecle- siásticos de la intendencia de Trujillo, 1781-1800}

\begin{tabular}{|c|c|c|c|c|}
\hline Nombre & $\begin{array}{c}\text { Doctrina y } \\
\text { residencia }\end{array}$ & Tipo de relación & Fecha & Fuente \\
\hline $\begin{array}{l}\text { José } \\
\text { Antonio } \\
\text { Polo } \\
\end{array}$ & $\begin{array}{l}\text { Ron, } \\
\text { provincia de } \\
\text { Chachapoyas }\end{array}$ & $\begin{array}{l}\text { Cobranzas del sínodo } \\
\text { del tercio de navidad }\end{array}$ & $26 / 03 / 1781$ & 1 \\
\hline $\begin{array}{l}\text { Joaquín } \\
\text { Solupe }\end{array}$ & $\begin{array}{l}\text { Pueblo de } \\
\text { Santiago de Cao }\end{array}$ & $\begin{array}{l}\text { Cobranzas del sínodo } \\
\text { del tercio de navidad }\end{array}$ & $23 / 04 / 1781$ & 2 \\
\hline \multirow{2}{*}{$\begin{array}{l}\text { Bernabé } \\
\text { Antonio } \\
\text { Caballero }\end{array}$} & \multirow{2}{*}{$\begin{array}{l}\text { Pueblo de } \\
\text { Otusco }\end{array}$} & $\begin{array}{l}\text { Nombramiento de } \\
\text { albacea }\end{array}$ & $23 / 12 / 1785$ & 3 \\
\hline & & $\begin{array}{l}\text { Inventario de bienes y } \\
\text { venta de propiedades }\end{array}$ & $13 / 03 / 1786$ & 4 \\
\hline $\begin{array}{l}\text { Matías } \\
\text { de Soto y } \\
\text { Soraluce }\end{array}$ & $\begin{array}{l}\text { Ramada de } \\
\text { San Roque, } \\
\text { Lambayeque }\end{array}$ & $\begin{array}{l}\text { Venta de Francisca } \\
\text { de } 16 \text { ańos y su hija } \\
\text { María Gabriela de } \\
1 \text { mes }\end{array}$ & $22 / 04 / 1786$ & 5 \\
\hline $\begin{array}{l}\text { Santiago } \\
\text { Ariztizabal }\end{array}$ & $\begin{array}{l}\text { San Marcos, } \\
\text { Cajamarca }\end{array}$ & $\begin{array}{l}\text { Poder general para } \\
\text { cobranzas }\end{array}$ & 09/12/1789 & 6 \\
\hline $\begin{array}{l}\text { Pedro } \\
\text { Damasco } \\
\text { Muñoz de } \\
\text { Pando } \\
\end{array}$ & $\begin{array}{l}\text { Olleros, } \\
\text { Chachapoyas }\end{array}$ & $\begin{array}{l}\text { Poder para cobrar el } \\
\text { sínodo }\end{array}$ & $16 / 12 / 1789$ & 7 \\
\hline $\begin{array}{l}\text { Juan José } \\
\text { Martínez } \\
\text { de Noriega } \\
\end{array}$ & $\begin{array}{l}\text { Pueblo de } \\
\text { Cajamarquilla, } \\
\text { Pataz }\end{array}$ & $\begin{array}{l}\text { Poder general para } \\
\text { cobranzas }\end{array}$ & $23 / 08 / 1791$ & 8 \\
\hline $\begin{array}{l}\text { Diego del } \\
\text { Castillo }\end{array}$ & $\begin{array}{l}\text { Huancabamba, } \\
\text { Piura }\end{array}$ & $\begin{array}{l}\text { Poder general para } \\
\text { negociaciones }\end{array}$ & $14 / 04 / 1792$ & 9 \\
\hline $\begin{array}{l}\text { Silvestre } \\
\text { Antonio } \\
\text { del Castillo }\end{array}$ & $\begin{array}{l}\text { Ciudad de } \\
\text { Piura }\end{array}$ & $\begin{array}{l}\text { Fianza de } 2,000 \text { pesos } \\
\text { por el remate de los } \\
\text { diezmos de Ayabaca } \\
\text { en el bienio de } 1793 \text { - } \\
1794\end{array}$ & $06 / 05 / 1793$ & 10 \\
\hline
\end{tabular}




\begin{tabular}{|l|l|l|l|l|}
\hline Nombre & \multicolumn{1}{|c|}{$\begin{array}{c}\text { Doctrina y } \\
\text { residencia }\end{array}$} & \multicolumn{1}{|c|}{ Tipo de relación } & Fecha & Fuente \\
\hline $\begin{array}{l}\text { Juan de } \\
\text { Noriega }\end{array}$ & $\begin{array}{l}\text { Pueblo de } \\
\text { Motupe }\end{array}$ & Cesión de capellanía & $06 / 08 / 1800$ & 11 \\
\hline $\begin{array}{l}\text { Manuel de } \\
\text { Unanue y } \\
\text { Urrutia }\end{array}$ & $\begin{array}{l}\text { Pueblo de } \\
\text { Mórrope }\end{array}$ & $\begin{array}{l}\text { Cobranza de los cinco } \\
\text { tercios de navidad }\end{array}$ & $24 / 12 / 1806$ & 12 \\
\hline
\end{tabular}

¿Qué beneficios obtuvo Tiburcio de Urquiaga con estas redes? Estas interacciones concretas, en las que los actores sociales -el referido vasco por un lado y los curas doctrineros por otro- intercambian bienes y servicios, tenían como interés para el primero crear conexiones con sujetos de todo crédito y abono en localidades distantes donde colocar sus mercaderías; y para los segundos, la realización efectiva de los encargos conferidos por cuenta de un poderoso vecino de la ciudad (González y Basaldúa, 2007, pp. 4-5). Por ello, la relación era bastante recíproca. $\mathrm{Al}$ respecto, Fisher sostiene que en las remotas aldeas de la sierra y en los inmensos espacios vacíos entre los asentamientos de las fronteras del imperio espańol, el control de la sociedad y, de modo vago, la autoridad política no eran agentes de la autoridad colonial fácilmente identificables, sino más bien terratenientes, sacerdotes y oficiales de la milicia local (Fisher, 2000, p. 79).

Los curas doctrineros ejercían el gobierno eclesiástico en sus jurisdicciones y gozaban de gran respeto en su comunidad, pero no es extrańo encontrarlos en la documentación ocupados en la comercialización de textiles y funcionando como agentes comerciales de confianza y conocedores de los mercados locales de sus doctrinas y los anexos de estas. En Huamachuco, cuando un personaje iniciaba una empresa, rara vez dejaba de hacerlo con el compadrazgo, la amistad y los 
capitales de un religioso, como acaeció con Jorge Terrones, bachiller en el hospital de San Andrés de Lima que "se apareció en esta ciudad [Trujillo] abatido de la suerte, se mantuvo algún tiempo al lado de una señora, sus necesidades lo obligaron a salir para la sierra a buscar minas, tocó en el pueblo de Cajabamba donde se hizo amigo del cura y compadre de los compadres de este $[\ldots]$ ". ${ }^{17}$

Articulada la red en su espacio -la intendencia de Trujillo-, al inicio de una coyuntura de auge, el comerciante estuvo en condiciones de poner en movimiento la maquinaria mercantil mediante diferentes modalidades, como la importación de efectos europeos por vía marítima de Cádiz al Callao y de allí a Trujillo, donde eran ingresados a sus almacenes para ser redistribuidos en las diferentes provincias del norte del virreinato.

\subsection{El tráfico a distancia}

Los grandes mercaderes norteńos tenían a los almacenistas limeños como sus habilitadores de mercancía, capital básico para el ejercicio de su rubro. Estas habilitaciones eran, en realidad, una inversión de los capitalinos en los mercaderes provinciales, esquema que estos últimos a su vez repetían en pequeña y mediana escala dentro de sus provincias (Aldana, 1999, pp. 142-143). Si bien es cierto que los grandes comerciantes

36 limeños trataron directamente con Espańa, existió un sector de comerciantes que vivía en provincia, pero accedió directamente al mercado metropolitano. Fue el caso de Tiburcio de Urquiaga que en la cúspide de su liderazgo comercial entabló relaciones directas con comerciantes gaditanos, debido a su

17 ARLL Presidencia del Departamento, causa ordinaria, leg. 455, exp. 67. 
condición de peninsular, a los contactos que estableció antes de partir al Perú y a su membresía en el tribunal del consulado como juez diputado de comercio. Estas circunstancias le garantizaron la confianza de sus pares peninsulares.

Las relaciones intercontinentales que se iniciaron poco después de su establecimiento en la ciudad cuentan con registros documentales precisos; sabemos que en octubre de 1785 inició negociaciones en la metrópoli con capitales líquidos de 27,215 pesos, provistos por el coronel José Antonio Cacho y de la Llata, vecino de Trujillo, y devueltos a su satisfacción en noviembre de 1787, además de 3,962 pesos en efectos de Castilla provistos por Blas Ignacio de Tellería y Tapia. En 1786, participaba en la red de sus parientes Cárdenas y Ballesteros, comerciantes establecidos en la ciudad norteńa que trabajaban con Juan Antonio Ballesteros en Sevilla, con Manuel Pascual Mendoza y Blas Ignacio de Tellería en Lima y con Tiburcio de Urquiaga y Domingo Milán de Acha en Trujillo. ${ }^{18}$

Más adelante, el 15 de setiembre de 1793, constituyó formalmente como sus factores a José de Molla, vecino y juez de comercio de Cádiz, y a Antonio Yraola, de la misma urbe, quienes se obligaron a enviar mercadería anual hasta un importe total de 40,000 pesos de general, en géneros y efectos que Urquiaga les solicitase y del dinero que les enviase corriendo a riesgo, en los primeros registros que salieran al Callao. En enero de 1794, Urquiaga realizó el primer envío de caudales líquidos a la península por un importe de 6,157 $1 / 2$ pesos de 128 cuartos, que fue invertido por sus factores

18 ARLL Protocolo, Vega Bazán, leg. 395 (1786-1788), e. 198, ff. 527-528; leg. 399 (1794-1797), e. 206, ff. 587-588. AGN Protocolo Aizcorbe, leg. 1785, ff. 1164, 1166-1166v. 
en los efectos solicitados. En febrero de 1795, se cargaron 50 marquetillas de cera (utilizadas para la iluminación) en la fragata Reina María Luisa, piloteada por el maestre José de Arceo. Los gaditanos corrieron con el riesgo del transporte de su puerto al del Callao, donde la mercadería fue entregada a Blas Ignacio de Tellería, apoderado de Tiburcio de Urquiaga y uno de los principales personajes del comercio de Lima, que entre 1784 y 1817 importó de Cádiz al Callao un monto de 23,677.375 reales de vellón (Mazzeo, 2012, p. 116). ${ }^{19}$

Tras el desembarco en Lima, Urquiaga y su apoderado se obligaron a remitir el dinero dentro de los seis primeros meses. Así, el 15 de setiembre de 1795, Tellería entregó 5,588 pesos 4 reales en doblones de cordoncillo (pesos duros de plata cordoncillo) a Juan José de Aristimuño, maestre de la fragata de guerra Rosalía, surta y anclada en el puerto del Callao y de regreso a España. ${ }^{20}$ El 9 de abril de 1796 se embarcaron las subsecuentes partidas, esta vez con un valor de 14,921 pesos de plata en el navío Levante siendo su maestre Fermín José de Minondo, las que fueron recibidas por Tellería y canceladas esta vez por Diego Lynch el 9 de diciembre de ese año. ${ }^{21}$ Las escrituras de remisiones cesan en 1796, probablemente se realizaron en las escribanías de Lima, pero el comercio de la casa Urquiaga y Aguirre continuó desarrollándose con normalidad hasta cerrar el periodo, prueba de ello son los bien aprovisionados almacenes y tiendas que en la primavera de 1797 ascendían a 26,126 pesos de un real. ${ }^{22}$

19 ARLL Protocolo, Vega Bazán, leg. 399 (1794-1797), c. 1, e. 69, ff.744v.-749.

20 ARLL Protocolo, Vega Bazán, leg. 399 (1794-1797), c. 1, e. 79, ff. 749.

21 ARLL Protocolo, Vega Bazán, leg. 399 (1794-1797), c. 2, e. 70, ff. 281-282 v. 22 ARLL Protocolo, Vega Bazán, leg. 399 (1794-1797), c. 3, e. 143, ff. 540-540v. 


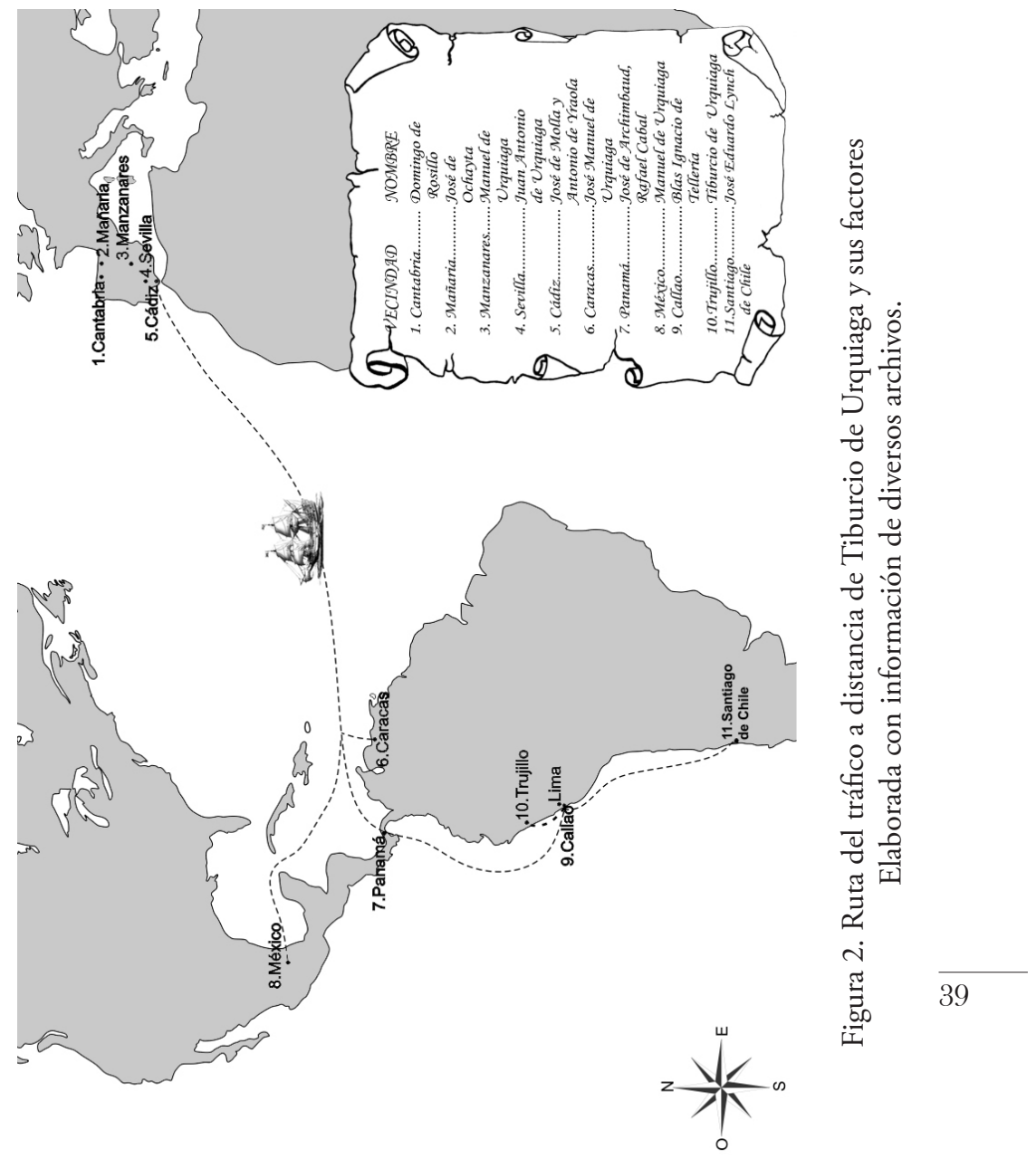




\subsection{El comercio intercolonial}

El Perú mantuvo un comercio fluido con Chile, dado que el Callao fue el principal puerto del Pacífico y Lima se había convertido en el centro de intercambio de importaciones y exportaciones hacia el norte con los puertos de Panamá, Guayaquil, Realejo, Sonsonate, Saña, Mórrope y Chérrepe, y por el sur, con Concepción, Pisco, Arica, Nazca, Chiloé y Coquimbo (Schülpmann, 2006, pp. 42-46, 68-69). Este comercio se llevaba a cabo fuera del sistema de flotas y galeones, al margen del control monopólico metropolitano. El comercio intercolonial dejaba importantes ganancias a los hispanoamericanos y a los extranjeros que conectaban regiones con un intenso tráfico que se proyectaba como un mercado exclusivo para los radicados en América. Su expansión tuvo como consecuencia que los comerciantes, tanto del Perú como de nueva España, lograran afianzar su poder frente a los flotistas metropolitanos (Mazzeo, 2011, p. 229).

La actividad de riesgo se sustentaba en el excedente de la producción de haciendas costeñas (azúcar) y de la sierra (cereales y textiles) destinados a mercados distantes. El estudio del panorama económico motivó que Tiburcio de Urquiaga adquiriera haciendas en la provincia de Huamachuco, que le proveían granos y ropa que fueron comercializados por vía marítima a través de los puertos de Santa, Guañape, Huanchaco, Malabrigo, Pacasmayo, Puerto Nuevo y Paita, que tomaron mayor dinamismo luego del reglamento de libre comercio. Por ello, el establecimiento de los miembros de la familia y relacionados en ciudades y pueblos cercanos a dichos embarcaderos resultó fundamental en la expansión de sus redes. Así, por ejemplo, los esposos piuranos Gregorio Gayeze y Manuela de Almanza fueron importantes corres- 
ponsales de Urquiaga, al punto que cuando la referida Manuela quedó viuda, Urquiaga se convirtió en su apoderado general. ${ }^{23}$

El caso más representativo fue el de Manuel de Urquiaga y Anachuri, el agente familiar establecido en las subdelegaciones del norte de la intendencia durante la última década del siglo XVIII. Desde el puerto de Paita se establecieron rutas con las ciudades de Guayaquil y Panamá, a donde los obrajeros de Huamachuco destinaban importantes partidas de ropa y otros productos. Los libros de las Reales Cajas registran a Manuel como "vecino del comercio de Trujillo", aunque radicó en Saña, Piura, Paita, Lambayeque y Catacaos. Manuel estableció relaciones comerciales con Estanislao Moreno, Manuel José Rebaza, Diego Rubio, Manuel Norberto Reyes y Manuel Diéguez. ${ }^{24}$

Tiburcio de Urquiaga también proyectó su comercio a mercados sureños; parte de la producción de sus obrajes se embarcaba en el puerto de Huanchaco en fragatas como la de los Vizcaínos con destino a Santiago de Chile, donde su hermano político Eduardo Lynch la desembarcaba para comercializarla a precios elevados debido a su calidad. Otros miembros del clan familiar establecidos en América fueron Manuel de Urquiaga, avecindado en México y miembro del Tribunal del Consulado de este Reino en 1815, y José Manuel de Urquiaga, vecino de Caracas en el mismo periodo y, aunque no tenemos referencia de intercambio de bienes y servicios con sus parientes trujilla-

23 Archivo Regional de Piura [en adelante ARP] Protocolo, Seminario, caja 75, e. 31, ff. $49 \mathrm{v} .-50$.

24 ARL Protocolo, Gómez Guevara, leg. 2 (1801), e. 296, ff. 230v. ARLL Protocolo, Concha y Mansubillaga, leg. 317 (1812), e. [roto], ff. 3-5v. AGN Colección Diéguez, Correspondencias, caja 3, doc. 1517. 
nos denotan la extensión de la red familiar en toda América hispana (Lohmann, 1972, pp. 387-388).

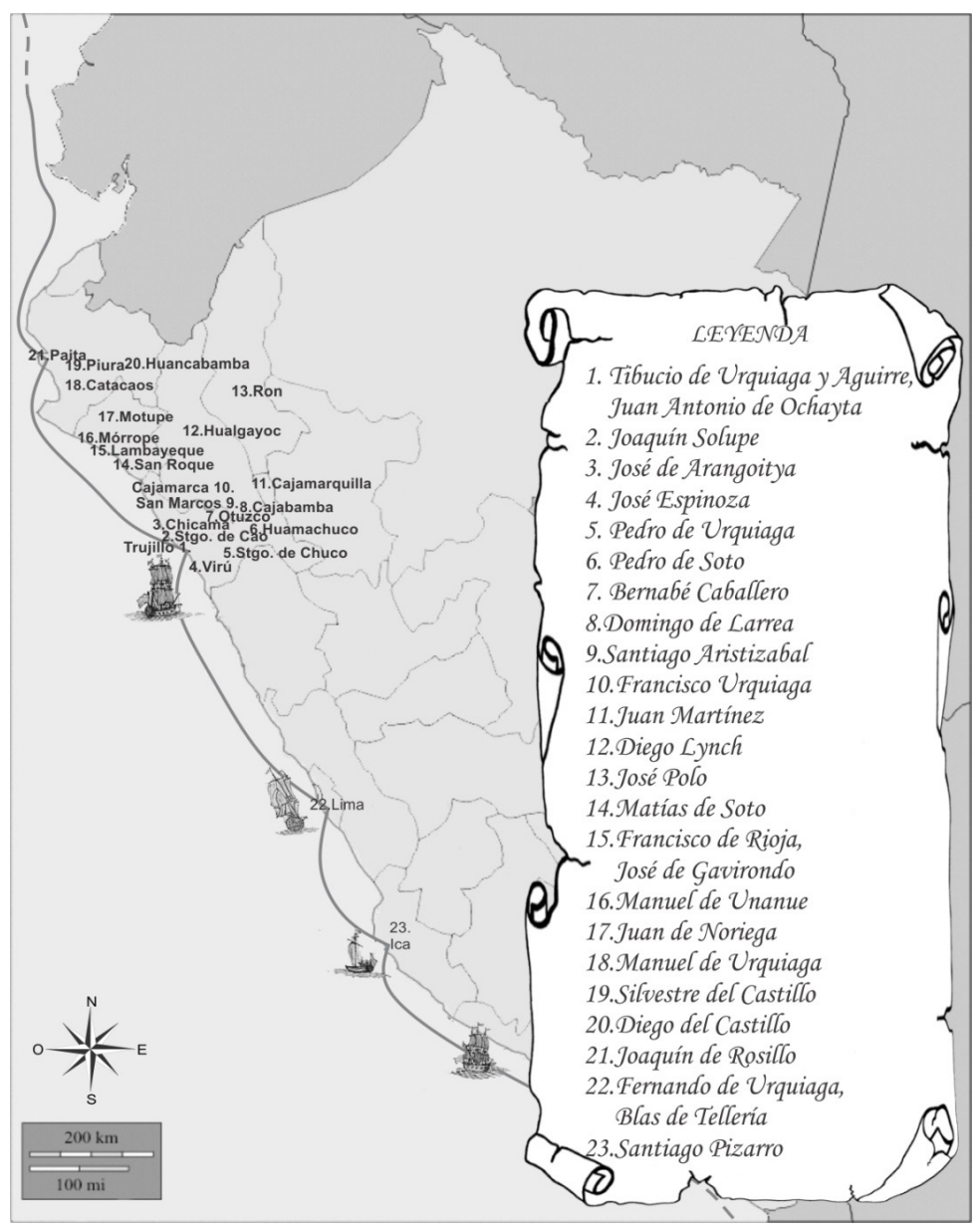

Figura 3. Red comercial americana de los Urquiaga y sus asociados en 1800

Elaborada con información de diversos archivos. 


\subsection{El comerciante almacenero}

Un comerciante almacenero generalmente era dueño de una casa comercial importante y compraba grandes cantidades de mercancías a los comerciantes exportadores establecidos en las capitales de los virreinatos, quienes a su vez exigían la adquisición de lotes completos y el pago inmediato. Aunque también existieron algunos en provincia como Tiburcio de Urquiaga, el mercado estaba controlado por grupos de hombres ricos (Brading, 1971, pp. 138-139). Las grandes casas importadoras en Trujillo no se limitaban a comerciar al mayoreo, cada almacenero tenía tiendas accesorias en sus casas de morada para ventas directas al público.

En Lima, las tiendas se situaron por separado, en unas se expendían bayetas, bayetones, pañetes y cordellates, tocuyos, jergas y demás tejidos del país "fabricados en las más de las provincias del virreinato"; en otras, artículos de lujo importados y había almacenes o encomenderías que vendían al por mayor cacao, suelas, cordobanes, jabones, carnes y pescados secos, aguardientes, vinos, vinagres, lonas de algodón, pitas en hilo, cobres en plancha y labrados, estaños, plomo, hilo acarreto, tablas de alerce y otros muchos renglones (Gallardo, 1808, p. 500). En Trujillo existieron numerosas tiendas y cajones instalados en la plaza mayor y calles inmediatas; las principales zonas comerciales fueron la calle del Arco (actual jirón Orbegoso), la de la Merced y la del Comercio (actual jirón Pizarro), además de otras repartidas en distintas manzanas de la ciudad, donde se vendían todo tipo de géneros de Castilla y del país, comestibles y otros artículos por separado semejante al caso capitalino.

Los almacenes de la casa comercial de Urquiaga tenían una gama de productos, que categorizados corresponden a los rubros de 1) textiles importados: seda, paño azul de primera de 
sedan, paño blanco de Barcelona, bayetas españolas, estameño, espolón, lamparillas, camellones, burato, buche, cortes de chupines, liso, felpichín, terciopelo, raso, paño, melania, castulensa, tafetán, estampilla, olán, estampillas, bretañas, holandillas, lanas de Holanda, candelete, choletas, zarasas aquimonadas, hilo de madejón, encajes, medias de lavanda y botones; 2) textiles de la tierra: bayetas, bayetones, pañete y jergas; 3 ) instrumentos e insumos para la industria obrajera: polvos azules, brasil, cardas, añil; 4) maderajes: cedro del Paraguay; 5) aceros: cuchillos, acero en barra y combas; 6) alimentos: especias como pimientos; 7) otros: papel, marquetillas de cera, cera de Piura, espejos grandes, marcos de cristal. ${ }^{25}$

Además, en las fachadas de sus residencias y dando a la calle tenían instaladas pulperías y tiendas accesorias, donde sus agentes bodegueros participaban en el expendio de productos al por menor y establecían clientes en función de las relaciones interpersonales, buen trato y precios que pudieran brindar, interactuaban de esta manera con diversos sectores sociales y se constituían en personas de mucha actuación. Su clientela era abastecida constantemente con géneros por Urquiaga, quien también regulaba los precios de acuerdo con las fluctuaciones del mercado, según las noticias que recibía tanto en el cabildo como en el juzgado de comercio. Figura-

44 ban entre sus agentes urbanos: Joaquín Monroy, maestro de sastre con tienda en la calle de La Merced, Patricio Gonzales, doméstico, y Eugenio Algarate, igualmente dependiente.

25 ARLL Protocolo, Vega Bazán, leg. 399 (1794-1797), c. 3, e. 143, ff. 540$540 \mathrm{v}$. 


\subsection{El comercio de la "ropa de la tierra"}

Aldana señala que la complementariedad económica fue el elemento fundamental del comercio y la especialización regional, el resultado de una racionalidad dirigida a aprovechar las ventajas comparativas de cada región. En Huamachuco la producción comprendió una amplia gama de artículos: bayetas, paños, pañetes, jergas, frazadas, bayetones, sayales, cordelletes, tocuyo y costales de lona; se produjeron también productos exclusivos, como los que llevaban el sello de "bayetas de Chusgón" (Aldana, 1999, p. 101; Zaugg, 1993, p. 184.). Esta especialización en cada una de las regiones aseguraba la apertura de mercados. La "ropa de la tierra" hecha en los obrajes de Huamachuco tenía segmentos de mercados variados, por un lado estaban los artículos de calidad superior destinados a las clases ricas y, por otro, productos de calidad media o inferior. La productividad de los empresarios textiles era dinámica y estaba sujeta a las coyunturas imperantes. Por ejemplo, en 1804, Tiburcio de Urquiaga propició la labranza de bayetones que no desmerecían en calidad con los de Espańa y proveyó con ellos a toda la ciudad al precio de 20 reales vara por su calidad. ${ }^{26}$

No obstante, instaurada la paz internacional, el precio volvió a subir y la abundancia de los efectos de España les restaba valor; el empresario reclamaba que el bayetón podría tener aceptación siempre y cuando su precio no excediera de 8 reales, pero como "con este no se costea el fabricante, se aplica a hacer ropa ordinaria, como son bayetas y pańetes, y para esto hila el indio 1 libra de lana cada día, y para los bayetones

26 AGN Tribunal del Consulado, Gobierno Político Administrativo, caja 6, doc. 125. 
solo 4 onzas, para que puedan salir de buena calidad y así se experimenta mucho atraso en el aumento de fábricas, y por tanto no tiene cuenta". ${ }^{27}$

La producción de los obrajes y haciendas de Huamachuco abastecía distintos mercados. El primero de ellos estaba conformado por la población interna de la provincia y sus poblados de Santiago de Chuco, Huamachuco, Otusco, Lucma, Cajabamba, y Simbal. Participaban en este negocio los agentes comerciales de los hacendados, quienes expendían los textiles a "precio de provincia". Es preciso destacar que esta producción no fue meramente artesanal, de carácter familiar y para un mercado local, por el contrario, las ventas se efectuaron en diferentes latitudes y generaban empleos directos e indirectos, que repercutieron en la economía de toda la provincia.

Los productos elaborados eran transportados a través de una extensa red de caminos con destino a diferentes partes del virreinato. La primera seguía la ruta desde las haciendas de Urquiaga a Huamachuco, Cajabamba, San Marcos y finalmente a Hualgayoc. Un segundo trayecto reunía la producción textil en Santiago de Chuco y descendía por Calipuy hasta llegar a Virú, Santa y luego hasta Lima, que era un importante mercado urbano consumidor de los textiles de Huamachuco. Un tercer recorrido concentraba la producción en la ciudad de Trujillo y descendía por Otusco y Simbal.

Lequanda observó que "los dueños de los obrajes serranos de Huamachuco se avecindaban en Trujillo y traían muchos productos para comercializar, sobre todo pañetes, bayetas,

27 AGN Tribunal del Consulado, Gobierno Político Administrativo, caja 6, doc. 125 . 
jergas, dinamizando el comercio trujillano" (1965, t. VII, p. 96). Esta ciudad era la primera entidad ordenadora del espacio colonial norteño y actuaba como núcleo desde donde se ejercía el poder económico y se consumía buena parte de la producción (Aldana, 2010, p. 110).

Por privilegio real, los productos de Trujillo pagaban solo el $6 \%$ de arancel por tierra y ningún arancel los que se embarcaban en Huanchaco y Pacasmayo, puertos en los que no se advertía comercio clandestino debido a la referida gracia. Influenciado por los preceptos de la ilustración, Urquiaga realizó fabricaciones experimentales de tocuyos de una vara de ancho, cuya calidad se decía que excedía a los de Cuenca y los convirtió en textiles preciados, como se comprueba con la venta de 4,000 varas en la ciudad de Santiago de Chile que hizo su hermano político Eduardo Lynch. Este le escribió "haberlos vendido con exceso en el precio y estimación a los de Cuenca, reencargándome le haga 6,000 varas cada año". ${ }^{28}$

Otro mercado extrarregional fue Potosí, que requería tejidos, muchos de los cuales provenían de los grandes centros textiles quiteños, cuya producción seguía la ruta por mar de Guayaquil y Callao. En este derrotero, los textiles de Huamachuco se enganchaban con los circuitos del sur hasta llegar al gran yacimiento (Aldana, 1999, p. 37, 46). La producción también fue enviada al mercado de Panamá con bastante frecuencia, según se constata a inicios del periodo decimonónico. Las utilidades líquidas que reportaba cada una de las haciendas de la provincia de Huamachuco oscilaban entre los 12,000 y 14,000 pesos de ventas anuales. El juez diputado de comercio calculó que en

28 AGN Tribunal del Consulado, Gobierno Político Administrativo, caja 6, doc. 125 . 
la provincia existían seis u ocho de estos complejos mayores, ${ }^{29}$ por lo que Aljovín y Rizo-Patrón (1998, p. 265) sugieren que las ganancias globales ascendieron a una suma entre 72,000 y 112,000 pesos. Sin embargo, considerando el mayor número de haciendas existentes en dicha provincia, las cifras debieron exceder los 200,000 pesos.

La rentabilidad estaba condicionada al dinamismo de los industriosos y sus trabajadores, quienes comercializaban la producción textil y ganaban un vasto conocimiento del mercado, así como lazos de amistad y de familia. La abundancia, proximidad y baratura de los insumos aseguraba poco desembolso y el incremento de las utilidades. La lana, por ejemplo, era suministrada por las ovejas que pastaban dentro de los linderos de la propiedad (cada obraje-hacienda mayor tenía en promedio 20,000 cabezas), luego se las trasquilaba y almacenaba en oficinas acondicionadas para tal fin, antes de su procesamiento.

El algodón era sembrado en el valle Guamanzaña, distante cuatro leguas de Virú, donde no existían haciendas debido a la escasez del agua y "solo lo siembran con las avenidas de los meses de febrero, marzo y abril". Con estos riegos, la fertilidad de la tierra producía una o dos cosechas de ají y algodón, y entre ambas no pasaban de 400 arrobas anuales. Estas especies eran compradas por Urquiaga a los cosecheros hasta la 48 cantidad de 200 arrobas al precio de 7 reales cada especie y eran puestas en Uningambal, distante 11 leguas a un precio que ascendía a 8 reales. ${ }^{30}$

29 AGN Tribunal del Consulado, Gobierno Político Administrativo, caja 6, doc. 125 .

30 AGN Tribunal del Consulado, Gobierno Político Administrativo, caja 6, doc. 125 . 
El valle del Santa fue también una zona productora de algodón y algunas haciendas se especializaron exclusivamente en su cultivo. Zevallos (1996, pp. 353-354) descubrió que Huamachuco también tenía valles calientes donde se plantaban y cosechaban cantidades considerables de algodón, pero algunos sembríos eran ocultados junto con los indios, por los tenientes de corregidor coludidos a su vez con los hacendados. Otros insumos necesarios en los obrajes eran la yerba de vidrio, azufre, alumbres, cochinilla, alcaparrosa y palos de tintes. En las inmediaciones de la ciudad de Trujillo existían plantaciones de "tocuyo" similar al palo del Brasil de Campeche, que se utilizaba como tinte en los obrajes; su precio era de 2 reales la arroba y se entregaba limpio y cortado al comprador. ${ }^{31}$

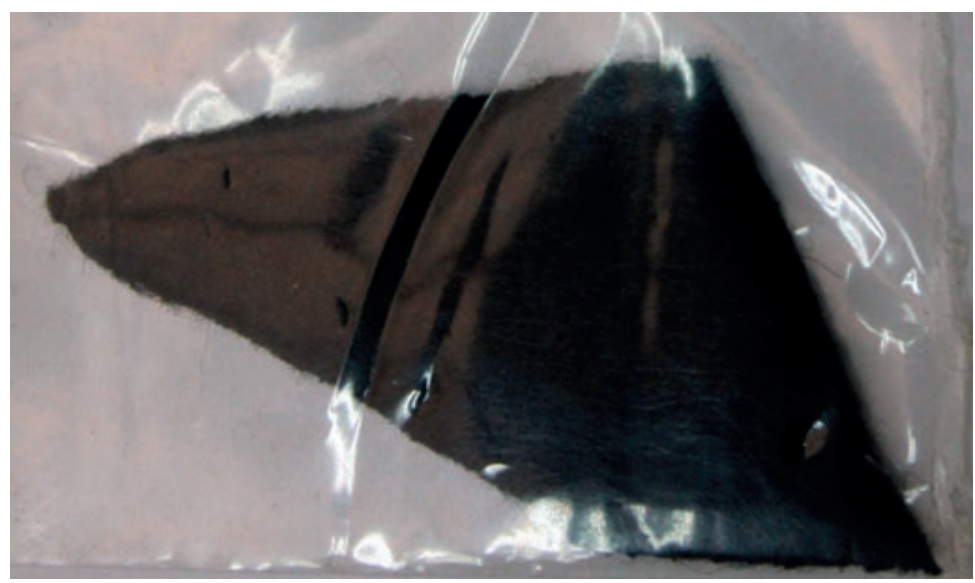

Figura 4. Muestra de bayetón de Uningambal hilado en rueca Fuente: AGN Tribunal del Consulado, Gobierno Político Administrativo, caja 6, doc. 125.

31 AGN Tribunal del Consulado, Gobierno Político Administrativo, caja 6, doc. 125 . 


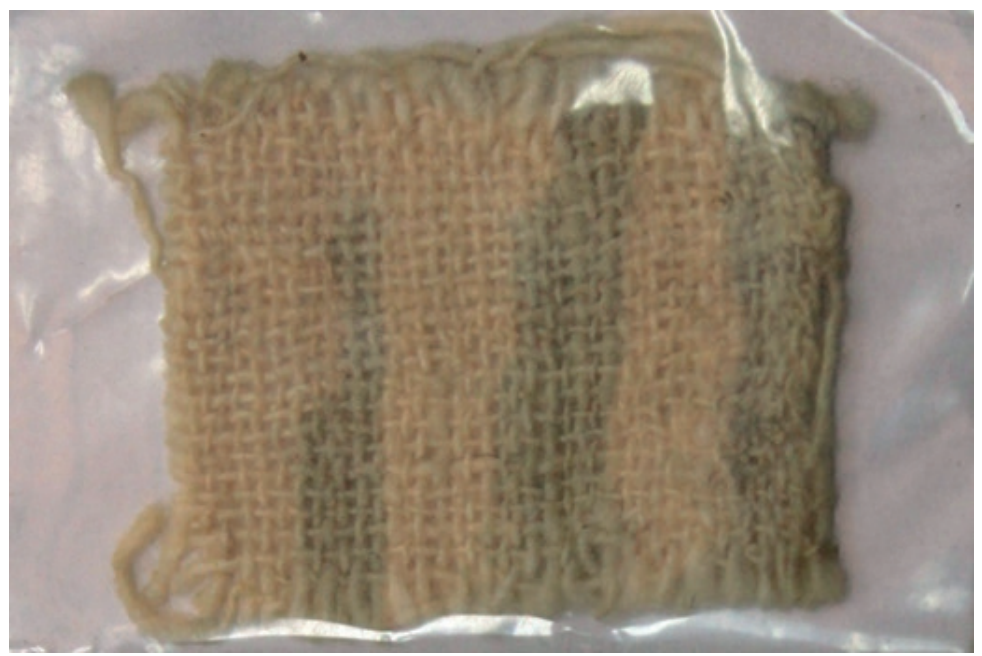

Figura 5. Muestra de tocuyo de Uningambal hilado en rueca Fuente: AGN Tribunal del Consulado, Gobierno Político Administrativo, caja 6, doc. 125

\section{Otros efectos: harinas, cereales, carneros, aguardiente y esclavos}

Durante el periodo virreinal, Huamachuco se constituyó en la despensa alimenticia de Trujillo, a donde se enviaban productos agrícolas, como legumbres, cereales, papas, maíz y ganado mayor y menor. Para acrecentar sus dividendos, en 1797 Tiburcio de Urquiaga ordenó la construcción de dos

50 molinos de trigo en sus haciendas, cuya producción, junto con los textiles y el ganado, fueron destinados a Trujillo y al cerro mineral de Hualgayoc mediante arrieros que regresaban cargados de sacos de sal para el consumo de las bestias de las estancias de la provincia. ${ }^{32}$

32 AGN Tribunal del Consulado, Gobierno Político Administrativo, caja 6, doc. 125 . 
La comercialización del ganado en la ciudad costera era controlada por su cabildo mediante "el ramo de abasto de carne". Los carneros, por ejemplo, eran beneficiados en el rastro del camal para luego pasar a las cocinas y convertirse así en la comida diaria de los trujillanos (Castañeda, 1996, pp. 170 171). En sus casas, los hacendados de la sierra tenían corrales acondicionados para la cría de ganado. En 1815, Urquiaga tenía hasta veinte carneros seleccionados entre los mejores de sus rebaños y conducidos por sus indios pastores desde sus haciendas a la ciudad, donde eran engordados. Parte de estos se destinaba a la alimentación diaria de la casa y otra, era comercializada. El "indio matancero" era el encargado de cuidar la salud de los moruecos, degollarlos, preparar las carnes, seleccionar los cuernos y pellejos, y conservar las grasas. ${ }^{33}$

Ahora bien, es evidente que los hacendados y estancieros más prominentes de la serranía de Huamachuco tenían como interés prioritario monopolizar este rubro en detrimento de otros grupos involucrados y su ventajosa posición en el gobierno les confería todas las prerrogativas necesarias. Así, por ejemplo, en la sesión del 6 de abril de 1813, el regidor fiel ejecutor Juan Antonio de Ochayta expuso que encontrándose supervisando la plaza de armas sorprendió a un sujeto enfermo vendiendo carne de capados. A continuación, procedió a arrestar el producto por ser "nocivo", pero se envió para la alimentación de los presos de la real cárcel. En consecuencia, los capitulares acordaron que en adelante expenderían la carne únicamente quienes tuvieran autorización. Pero la reglamentación fue insuficiente frente a las toneladas de carne que ingresaban diariamente a la ciudad. ${ }^{34}$

33 ARLL Cabildo, causa criminal, leg. 93, exp. 1649.

34 ARLL, Cabildo, Sesiones de Cabildo, Libro 19 (1812-1814), ff. 91v.-92. 


\section{Cuadro 2. Compra-venta de esclavos de los Urquiaga y sus relacionados}

\begin{tabular}{|c|c|c|c|c|c|}
\hline Vendedor & Comprador & $\begin{array}{c}\text { Nombre } \\
\text { del } \\
\text { esclavo }\end{array}$ & $\begin{array}{l}\text { Valor en } \\
\text { pesos }\end{array}$ & Fecha & Fuente \\
\hline $\begin{array}{l}\text { Petronila de } \\
\text { Anachuri }\end{array}$ & José López & Joaquín & 300 & $03 / 09 / 1780$ & 13 \\
\hline $\begin{array}{l}\text { Josefa de } \\
\text { Alvirena }\end{array}$ & $\begin{array}{l}\text { Tiburcio de } \\
\text { Urquiaga }\end{array}$ & $\begin{array}{l}\text { [desco- } \\
\text { nocido] }\end{array}$ & 400 & $29 / 08 / 1785$ & 14 \\
\hline $\begin{array}{l}\text { Tiburcio de } \\
\text { Urquiaga }\end{array}$ & $\begin{array}{l}\text { Manuel de } \\
\text { Bracamonte }\end{array}$ & $\begin{array}{l}\text { José María } \\
\text { Merino }\end{array}$ & 275 & $19 / 05 / 1793$ & 15 \\
\hline $\begin{array}{l}\text { Tiburcio de } \\
\text { Urquiaga }\end{array}$ & $\begin{array}{l}\text { Manuel de } \\
\text { Urquiaga }\end{array}$ & Domingo & 150 & $01 / 05 / 1797$ & 16 \\
\hline $\begin{array}{l}\text { Tiburcio de } \\
\text { Urquiaga }\end{array}$ & $\begin{array}{l}\text { Juan Antonio } \\
\text { de Ochayta }\end{array}$ & $\begin{array}{l}\text { José } \\
\text { Manuel }\end{array}$ & 200 & $21 / 06 / 1797$ & 17 \\
\hline $\begin{array}{l}\text { Francisca del } \\
\text { Risco }\end{array}$ & $\begin{array}{l}\text { Tiburcio de } \\
\text { Urquiaga }\end{array}$ & Salvador & 500 & $07 / 09 / 1797$ & 18 \\
\hline $\begin{array}{l}\text { Petronila de } \\
\text { Urquiaga }\end{array}$ & Juan Morillas & Josefa & 500 & 05/09/1798 & 19 \\
\hline $\begin{array}{l}\text { Josefa de } \\
\text { Alvierna }\end{array}$ & $\begin{array}{l}\text { Petronila de } \\
\text { Urquiaga }\end{array}$ & Petrona & 500 & $10 / 10 / 1798$ & 20 \\
\hline $\begin{array}{l}\text { Francisco de } \\
\text { Urquiaga }\end{array}$ & $\begin{array}{l}\text { Mariano } \\
\text { Navarrete }\end{array}$ & Juan & 500 & 19/11/1799 & 21 \\
\hline $\begin{array}{l}\text { Diego } \\
\text { Ganoza }\end{array}$ & $\begin{array}{l}\text { Juan Antonio } \\
\text { de Ochayta }\end{array}$ & Asención & 460 & $29 / 11 / 1799$ & 22 \\
\hline $\begin{array}{l}\text { Rosa de } \\
\text { Ubilla } \\
\end{array}$ & $\begin{array}{l}\text { Francisco de } \\
\text { Urquiaga }\end{array}$ & Juan & 400 & 05/09/1799 & 23 \\
\hline $\begin{array}{l}\text { Francisco de } \\
\text { Urquiaga }\end{array}$ & Josefa Guardia & Dominga & 400 & $18 / 02 / 1800$ & 24 \\
\hline $\begin{array}{l}\text { Juan } \\
\text { Antonio de } \\
\text { Ochayta }\end{array}$ & Josefa Palacios & $\begin{array}{l}\text { María } \\
\text { Asunción }\end{array}$ & 470 & $24 / 04 / 1801$ & 25 \\
\hline $\begin{array}{l}\text { Francisco } \\
\text { Rodríguez }\end{array}$ & $\begin{array}{l}\text { Tiburcio de } \\
\text { Urquiaga }\end{array}$ & José & 460 & $21 / 08 / 1805$ & 26 \\
\hline
\end{tabular}




\begin{tabular}{|l|l|l|c|c|c|}
\hline \multicolumn{1}{|c|}{ Vendedor } & Comprador & $\begin{array}{c}\text { Nombre } \\
\text { del } \\
\text { esclavo }\end{array}$ & $\begin{array}{c}\text { Valor en } \\
\text { pesos }\end{array}$ & Fecha & Fuente \\
\hline $\begin{array}{l}\text { Domingo de } \\
\text { las Casas }\end{array}$ & $\begin{array}{l}\text { Juan Antonio } \\
\text { de Ochayta }\end{array}$ & Loreta & 600 & $02 / 12 / 1814$ & 27 \\
\hline $\begin{array}{l}\text { Tiburcio de } \\
\text { Urquiaga }\end{array}$ & $\begin{array}{l}\text { Juan Alejo } \\
\text { Palacios }\end{array}$ & Juana & 400 & $09 / 12 / 1814$ & 28 \\
\hline $\begin{array}{l}\text { Tiburcio de } \\
\text { Urquiaga }\end{array}$ & Luisa Sayal & $\begin{array}{l}\text { Nicolás } \\
\text { Lazo }\end{array}$ & 200 & $14 / 04 / 1817$ & 29 \\
\hline $\begin{array}{l}\text { Juan } \\
\text { Antonio de } \\
\text { Ochayta }\end{array}$ & $\begin{array}{l}\text { Antonio de } \\
\text { Nieves }\end{array}$ & $\begin{array}{l}\text { Negra } \\
\text { bozal }\end{array}$ & 400 & $27 / 02 / 1817$ & 30 \\
\hline $\begin{array}{l}\text { Mariano } \\
\text { García }\end{array}$ & $\begin{array}{l}\text { Juan Antonio } \\
\text { de Ochayta }\end{array}$ & $\begin{array}{l}\text { Cipriano } \\
\text { Toledo }\end{array}$ & 300 & $08 / 02 / 1820$ & 31 \\
\hline $\begin{array}{l}\text { Gertrudis } \\
\text { Luna } \\
\text { Victoria }\end{array}$ & $\begin{array}{l}\text { Petronila de } \\
\text { Urquiaga }\end{array}$ & Petrona & 500 & $23 / 06 / 1821$ & 32 \\
\hline $\begin{array}{l}\text { Juan Luis } \\
\text { Chacat }\end{array}$ & $\begin{array}{l}\text { Juan Antonio } \\
\text { de Ochayta }\end{array}$ & Fructuoso & 250 & $11 / 06 / 1823$ & 33 \\
\hline $\begin{array}{l}\text { José María } \\
\text { Cárdenas }\end{array}$ & $\begin{array}{l}\text { Pedro Antonio } \\
\text { de Urquiaga }\end{array}$ & $\begin{array}{l}\text { Antonio } \\
\text { Prado }\end{array}$ & 300 & $19 / 06 / 1823$ & 34 \\
\hline $\begin{array}{l}\text { Petronila de } \\
\text { Urquiaga }\end{array}$ & $\begin{array}{l}\text { Francisca } \\
\text { Villalobos }\end{array}$ & Francisca & 500 & $30 / 09 / 1824$ & 35 \\
\hline $\begin{array}{l}\text { Antonio de } \\
\text { Urquiaga }\end{array}$ & $\begin{array}{l}\text { Manuel } \\
\text { Barriga }\end{array}$ & José Luis & 300 & $25 / 06 / 1827$ & 36 \\
\hline $\begin{array}{l}\text { Petronila de } \\
\text { Urquiaga }\end{array}$ & $\begin{array}{l}\text { Antonio } \\
\text { Carrión }\end{array}$ & $\begin{array}{l}\text { José } \\
\text { Oscos }\end{array}$ & 200 & $06 / 05 / 1828$ & 37 \\
\hline $\begin{array}{l}\text { Manuela de } \\
\text { Urquiaga }\end{array}$ & $\begin{array}{l}\text { Pablo de } \\
\text { Madalengoitia }\end{array}$ & Rosario & 450 & $09 / 04 / 1829$ & 38 \\
\hline
\end{tabular}

El juez diputado de comercio participó también en la comercialización de aguardiente en diferentes puntos de la intendencia de Trujillo. El vino y el aguardiente procedían de Are- 
quipa, Pisco e Ica, centros que gozaban de una importante demanda en los mercados de Lima y del norte del Perú, plazas unidas mediante embarcaciones de cabotaje y gran calado (Brown, 2008, pp. 106-107). A inicios del siglo XIX, parte de este mercado fue controlado por los Urquiaga, quienes desde el 9 de agosto de 1801 introdujeron a su intendencia, mediante las correspondientes guías, un número no precisado de botijas de aguardientes, las que eran comercializadas por su apoderado José de Gavirondo. ${ }^{35}$

Otra característica común de todos los comerciantes fue su dedicación en forma paralela a las operaciones de crédito, cuyos rentables intereses iban del 4 al 10\% para avíos de recuas, anticipos a itinerantes. Así, por ejemplo, el 5 de agosto de 1818 Tiburcio de Urquiaga otorgó un préstamo de 1,500 pesos al comerciante Domingo Benites con un interés del 8\%. ${ }^{36}$

El tráfico de esclavos fue un rubro que comprometió a buena parte de la élite trujillana; en el caso de la familia Urquiaga, sus miembros (varones y mujeres) participaron también en esta actividad. En el periodo virreinal, la necesidad de esclavos para el servicio doméstico, la proliferación de cultivos de azúcar, algodón y tabaco en los valles inmediatos requirió mano de obra esclava, que fueron traídos de Centroamérica y de Lima. En Trujillo existieron comerciantes especializa-

54 dos en este tráfico, como el poderoso clan de los Larrea, que pronto asociaron a Francisco de Paula Urquiaga en sus negociaciones.

35 ARLL Protocolo, Vega Bazán, leg. 401 (1800-1801).

36 ARLL Protocolo, Ortega y Salmon, leg. 1818-1819 (I), e. 33, ff. 56-57. 


\section{Conclusiones}

Tiburcio de Urquiaga y Aguirre se constituye en un personaje representativo de la sociedad trujillana de antiguo régimen del periodo decimonónico. Se ha determinado que procedía de una familia de la aristocracia de Santa María de Mañaria, de Durango (Vizcaya), que a mediados del siglo de las luces se encontraba en un proceso de expansión de sus vinculaciones mediante convenientes matrimonios de sus hijos y su colocación en las principales localidades de la península para acrecentar de esta manera sus actividades y relaciones, incluso con miembros de la dinastía imperial hispana. Dentro de dichas estrategias, la función de Tiburcio de Urquiaga se circunscribió a su desarrollo personal y expansión de los intereses familiares a ultramar en una coyuntura propicia con el incentivo de la emigración de jóvenes vizcaínos y el aseguramiento de puestos de gobierno en las nuevas locaciones donde fueron a servir.

Su destacamento a Trujillo, Perú, en 1771 evidencia su estatus social, donde conformó una red familiar extendida dedicada al comercio. El desenvolvimiento escalonado del personaje en la ciudad, incluidos su residencia, vecindad, matrimonio e ingreso al cabildo; estuvo orientado a su integración en el medio controlado por poderosas familias criollas. El peninsular Urquiaga representa un caso característico, pues no conoció a sus suegros, por lo que no se corresponde con las denominadas "ramas pegadizas" de Céspedes del Castillo, en cambio, interactuó con una red de parientes políticos que le permitieron acrecentar sus vinculaciones.

En junio de 1797, su esposa falleció y dejó a sus hijos en minoría de edad, por lo que ese mismo año Tiburcio de Urquiaga 
contrajo segundas nupcias con Josefa Lynch, hija de un importante comerciante irlandés. Visto desde el punto de vista familiar, Josefa asumió el cuidado de los hijos y desde el punto de vista mercantil, el matrimonió significó el sello de una alianza de dos socios. Lynch comercializaba el mineral de Hualgayoc y tenía parientes y agentes en diferentes países de la América hispana. A su vez, los hijos de Diego Lynch estuvieron vinculados matrimonialmente con importantes familias del virreinato.

En cuestiones estatales, entre 1775 y 1785, los visitadores generales Areche y Escobedo introdujeron en el Virreinato del Perú el programa borbónico de reformas administrativas, judiciales y financieras para hacer la autoridad imperial más firme, convencidos de que esta meta produciría rentas más altas para la real hacienda. Para esto, la Corona contó con un equipo de militares y burócratas que se movilizaron a América; Urquiaga fue uno de esos agentes que participó activamente en la instrumentación de las reformas, lo que le permitió ser parte del sector que pasó a controlar la región norte. El renovado cabildo evidencia la modernización de las prácticas y la existencia de una política de intereses, de la que Urquiaga fue parte como regidor perpetuo de la ciudad.

Fue también juez diputado de comercio, uno de sus cargos más representativos (1797-1820). La creación de nuevos consulados y legislaciones plantearon que el comercio no fuera el único objetivo, sino que se pretendía también fomentar la industria y la agricultura, aunque esto fracasó en algunas economías como la sevillana. En Trujillo, Tiburcio de Urquiaga, como representante del Tribunal del Consulado, incentivó la producción de tejidos de calidad (tocuyo y bayetón), que superó a la manufactura de Cuenca. Emprendió campañas de capacitación de sus obrajeros hilanderos para que aprendie- 
ran a maniobrar el torno y obtener una hechura más fina que con el huso, que era la práctica común. También propició el sembrío de alcaparrosa y alumbre en vetas de los territorios yungas de Uningambal. En este sentido, los nuevos consulados fueron producto de una nueva generación que siguió un plan enmarcado en el pensamiento de la Ilustración.

En el aspecto económico, las fuentes de riqueza de Tiburcio de Urquiaga fueron la agricultura, ganadería, industria textil, minería y comercio. Articuló su red a través de dos canales, el secular y eclesiástico; en el primero, desempeñó cargos de confianza con vecinos de distintas ciudades del virreinato; en el segundo, su prestigio fue catapultado mediante la confianza que le confirieron presbíteros doctrineros. Así, el comerciante contaba con una extensa red que se puso en movimiento en una coyuntura de auge con el descubrimiento del cerro mineral de Hualgayoc en 1771, la liberación del comercio en 1778 y el despegue de las manufacturas textiles huamachuquinas en 1780. Su comercio tuvo volúmenes importantes en su medio, en 1785 inició sus negociaciones con capitales líquidos de 27,215 pesos, en 1786 también participaba en la red de sus parientes Cárdenas y Ballesteros, y en 1793 constituyó formalmente factores en Cádiz y Callao y hacía remisiones de mercadería de hasta 40,000 pesos anuales.

A nivel intercolonial comercializó la producción de haciendas costeńas y de la sierra que se embarcaba de puertos y caletas como Santa, Guañape, Huanchaco, Malabrigo, Pacasmayo y Paita, y tomó mayor dinamismo luego del reglamento de libre comercio. Fue también almacenero, dueño de una casa comercial importante con mercaderías compradas en lotes que se expedían al mayoreo y menudeo en sus tiendas accesorias a sus casas de morada, en las que también se despachaban 
textiles producidos en la sierra inmediata y que gozaban de gran demanda. Otro rubro en los que el vasco tuvo participación importante fue la comercialización de aguardiente, ganado, productos de pan llevar, cereales y esclavos en diferentes puntos de la intendencia de Trujillo.

En 1780, Urquiaga se estableció definitivamente en Trujillo y en 1786 ganó la certificación de hidalguía y vizcainía en la Real Cancillería de Valladolid; los distintivos de exhibir hábitos de una orden militar resultaron secundarios frente al despliegue de energía con una patente fortuna diversificada en casa comercial, crédito, conocidos obrajes-haciendas y propiedades urbanas; fortuna en la que también participaron sus hijos del primer y segundo matrimonio. En el medio donde se asentó Tiburcio de Urquiaga, los patrimonios de las familias de la élite trujillana fueron formándose a través de la adquisición y potenciación de sus haciendas, acumulación de bienes inmuebles, rentas, producción, comercialización, ejercicio de altos cargos políticos-honoríficos y la gestión de sus estados nobiliarios. A estos se integraban elementos inmateriales, como el apellido, emblemas, títulos y signos de honor que se convirtieron en aspectos determinantes de su jerarquización. La consolidación de sus grandes linajes se produjo a partir de una estrecha relación entre las formas de organización familiar, la envergadura del patrimonio familiar y las formas de difusión transgeneracional.

La fortuna de Tiburcio de Urquiaga, en 1797, es el ejemplo más contundente de las inversiones de un miembro de la élite trujillana, que diversificó sus carteras económicas y contribuyó a modificar la fisonomía social y económica del periodo virreinal. En la cúspide de su solvencia económica llegó a amasar 181,462 pesos. Sus conocimientos de la economía y 
su participación en los poderes locales le permitieron además estar al tanto de las fluctuaciones de los precios y el aseguramiento de sus productos y mercados.

La riqueza acumulada por Tiburcio en 1797 , fecha en la que hemos identificado su primer capital de bienes tras la muerte de su primera esposa, estuvo bien equilibrada. Su obraje-hacienda de Llaray representaba el 37\% [38,116 pesos] del total de sus inversiones, incluida las inyecciones de fuertes capitales en la mejora de todas las oficinas y del ganado. El segundo valor porcentual relevante fue la mercadería o efectos de Castilla con $25 \%$ [26,125 pesos], seguían las casas de Trujillo con $15 \%$ $[15,609$ pesos], fuera del menaje con 4\% [3,853 pesos], los esclavos con 3\% [3,950 pesos], las alhajas, oro y diamante con $3 \%$ [2,544 pesos] y con el mismo porcentaje, la plata labrada [3,164 pesos]. Finalmente, las dependencias o cartera pesada corresponden al 9\% [9,310 pesos] del total de inversiones. El cúmulo de bienes sumó 102,675 pesos 3 1/2 reales. ${ }^{37}$

En los siguientes años, durante su alianza matrimonial con los Lynch, su fortuna se incrementó vertiginosamente, no tan solo en su numerario, sino en el dinamismo comercial combinado de Urquiaga y Lynch, cuyos agentes comerciales se encontraban virtualmente en toda América e inclusive en muchas locaciones de Europa. En 1801, en vías de invertir en el sector obrajero-hacendado hizo un préstamo a su suegro de 49,000 pesos para adquirir Uningambal, con lo que su fortuna ascendió a 151,676 pesos. Tres años más tarde adquirió la casa de las Cajas Reales en 8,000 pesos que le aseguraron además rentas constantes, su fortuna entonces al- 
canzaba 159,676 pesos. En 1805, invirtió en la compra de la chacra de Santo Tomás de Villanueva en 7,186 pesos, lo que hizo subir su capital a 166,862 pesos.

En 1807, Llaray y Uningambal se encontraban desamortizados y saneados de todo censo y gravamen. En ambas, se hicieron importantes inversiones según consta en sus propias declaraciones "empezó a laborarla en el caudal común, o lo que rendían las haciendas de Llaray y Uningambal hasta en estado de ponerlas en estado de 30,000 pesos" [con inversiones inyectadas en cada una de ellas]. Para esas fechas, su fortuna alcanzó el pico más elevado, 181,462 pesos.
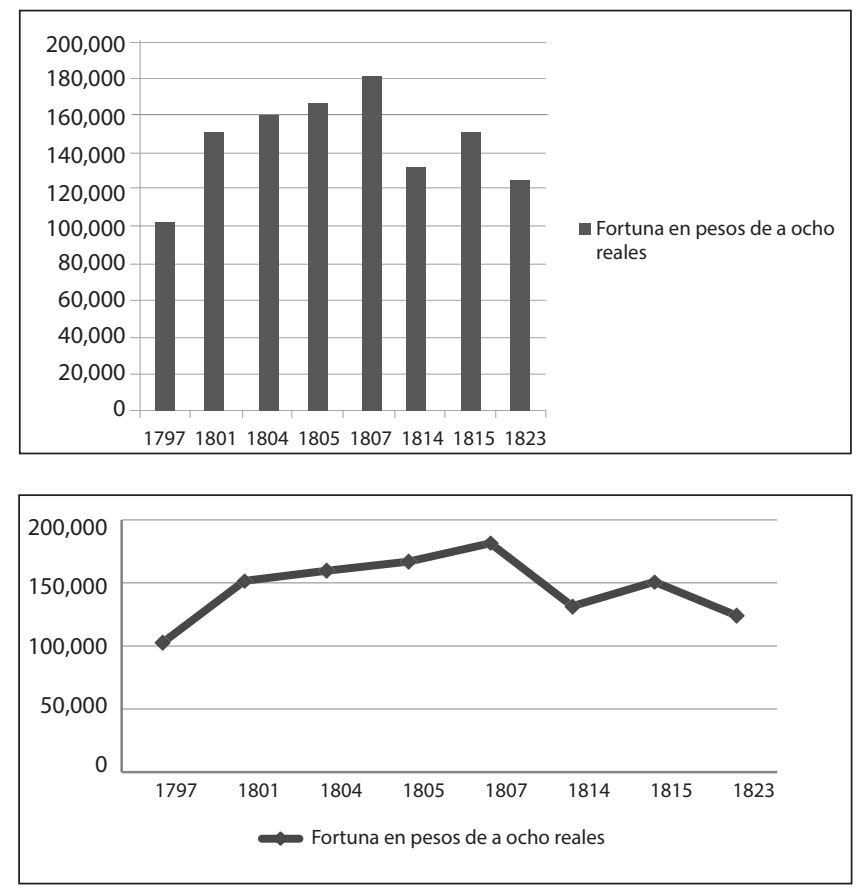

Figura 6. Evolución del cúmulo de inversiones de Tiburcio de Urquiaga, 1797-1823 
Basado en documentos de ARLL Protocolo, Vega Bazán, leg. 399 (1794-1797), c. 3, e. 143. AAT Jurisdicción Eclesiástica, Sección de documentos de la hacienda de Uningambal, expediente de remate de Uningambal en 1801. ARLL Intendencia, causa ordinaria, leg. 341, exp. 1020. ARLL Presidencia del Departamento, causa ordinaria, leg. 455, exp. 67. ARLL Cabildo, compulsa, leg. 104, exp. 1773, c. 2. ARLL Intendencia, compulsa, leg. 397, exp. 2141.

En los años siguientes, las coyunturas políticas desfavorables y el desenlace de sus juicios de parentela le ocasionaron una crisis, como se observa en el gráfico. El constante y elevado desembolso en las costas procesales, las horas/hombre invertidas para realizar sus tareas y responsabilidades se vieron comprometidas con los juicios. Finalmente, en 1814 se emitió el auto definitivo mediante el cual perdió Uningambal con pérdidas calculadas en 50,000 pesos, en consecuencia su fortuna mermó a 131,462 pesos.

Su ventajosa posición en el juzgado privativo de aguas y sus pujantes inversiones y mejoras en Santo Tomás de Villanueva, calculadas en 19,388 pesos, le permitieron compensar las pérdidas en inversiones (su fortuna se volvió a incrementar a 150,850 pesos), la chacra evolucionó a una hacienda de medianas dimensiones con dos fuentes de agua constantes: $\mathrm{Pu}-$ quio Alto y La Mochica, pero estas inversiones pronto se perderían. En 1823, Tiburcio de Urquiaga y sus cuñados estaban finalizando todas las querellas que les habían consumido en plena coyuntura de la independencia. En esas circunstancias, Urquiaga, finalmente, cedió la hacienda de Santo Tomás a su esposa Josefa Lynch, cuya tasación ascendió a 26,574 pesos, un valor muy superior a los obrajes-haciendas de San Ignacio y Chala juntos y más bien equiparable al valor de Condor- 
chuco. En ese año, su fortuna se vio disminuida en 124,276 pesos, un final que escapó a sus estrategias trazadas.

Recibido: 25 de setiembre de 2017

Aprobado: 24 de febrero de 2018

\section{Bibliografía}

Aldana, $S$.

(1999) Poderes en una región de frontera: Comercio y familia en el norte (Piura, 1700-1830). Lima: Panaca.

Aldana, S.

(2010) Orden y desorden: región y ciudad entre el Virreinato y la República. Trujillo del Perú. En C. Mazzeo (Ed.), Las relaciones de poder en el Perú. Estados, regiones e identidades locales. Siglos XVII-XIX (pp. 86128). Lima: Fondo Editorial de la Pontificia Universidad Católica del Perú.

Aljovín, C. y Rizo-Patrón, P.

(1998) La élite nobiliaria de Trujillo de 1700 a 1830. En S. O’Phelan Godoy e Y. Saint-Geours (Eds.), El norte en la historia regional (pp. 241-293). Lima: IFEACIPCA.

Brading, D.

(1971) Mineros y comerciantes en el México borbónico (17631810). México: Fondo de Cultura Económica.

Brown, K.

(2008) Borbones y aguardiente. La reforma imperial en el sur peruano: Arequipa en visperas de la Independencia. Lima: Banco Central de Reserva del Perú e IEP.

Castañeda, J.

(1996). Notas para una historia de la ciudad de Trujillo del Perú en el siglo XVII. En L. Millones, La tradición 
andina en tiempos modernos (pp. 159-189). Osaka: National Museum of Ethnology.

Contreras, C.

(1999) La minería peruana en el siglo XVIII. En S. O’Phelan Godoy (Comp.), El Perú en el siglo XVIII (pp. 1337). Lima: Pontificia Universidad Católica del Perú.

Fisher, J.

(2000) El Perú borbónico, 1750-1824. Lima: Instituto de Estudios Peruanos.

Gallardo, D. M.

(1808) Almanak mercantil o Guia de comerciantes para el año de 1808. Contiene una noticia de los derechos que pagan a su entrada y salida en el Reyno, tanto los géneros extranjeros como los nacionales: juzgados, establecimientos de comercio y fábricas en las principales plazas; nombres de los comerciantes y fabricantes, cónsules extranjeros, corredores de cambio y efectos: almacenes más notables: reducción de monedas, pesos y medidas a las de Castilla: cálculo del valor diario de los Vales Reales, con otras muchas noticias que interesan al comercio nacional de América y extranjero. Madrid: Imprenta de Vega y Compañía, calle de Capellanes, con Real Privilegio exclusivo.

González, C. y Basaldúa, M.

(2007) La formación de redes sociales en el estudio de actores y familias. Perspectiva de estudio en historia y antropología. Redes, Revista hispana para el análisis de redes sociales, 12 (8), 1-25.

Hernández, E.

(2008) La élite piurana y la independencia del Perú: la lucha por la continuidad en la naciente República (17501824). Lima: Universidad de Piura, Pontificia Universidad Católica del Perú. 
Lamikiz, X.

(2008) Redes mercantiles y formación de la familia en el comercio colonial español durante el siglo XVIII. Nuevo Mundo, Mundos Nuevos. Consulta: 10 octubre 2012. Recuperado de https://journals.openedition. org/nuevomundo/20162

Lequanda, J.

(1965) Descripción geográfica de la ciudad y partido de Trujillo. Mercurio Peruano, edición facsimilar. Lima: Biblioteca Nacional del Perú. t. VII.

Lohmann, G.

Documentación oficial española. Lima: Comisión Nacional del Sesquicentenario de la Independencia del Perú. t. XXII, v. 1.

Mazzeo, A. C.

(1994) El comercio libre en el Perú. Las estrategias de un comerciante criollo. José Antonio de Lavalle y Cortés, conde de Premio Real. 1777-1815. Lima: Fondo Editorial de la PUCP.

Mazzeo, A. C.

(2011) Comerciantes en conflicto, la independencia en el Perú y la transformación de la élite mercantil 17801830. Anuario del Instituto de Historia Argentina, 11, 243-258. Recuperado de http://www.memoria.fahce.unlp.edu.ar/art_revistas/pr.5252/pr.5252.pdf

64 Mazzeo, A. C.

(2012) Gremios mercantiles en las guerras de independencia. Perú y México en la transición de la Colonia a la República, 1740-1840. Lima: Banco Central de Reserva del Perú e Instituto de Estudios Peruanos.

Rizo-Patrón, P.

(2001) Linaje, dote y poder. La nobleza de Lima de 1700 a 1850. Lima: Pontificia Universidad Católica del Perú. 
Schülpmann, J.

(2006) Cartas edificantes sobre el comercio y la navegación entre Perú y Chile a comienzos del siglo XVIII. Correspondencias y contabilidad de una compañia comercial. 1713-1730. Lima: Instituto Francés de Estudios Andinos y BCRP.

Zaugg, M.

(1993) Textile production and structural crisis: the case of late colonial Peru (Tesis para optar el grado de Doctor en Filosofía). Liverpool: University of Liverpool.

Zevallos, J.

(1996) Los fundadores y primeros pobladores de Trujillo del Perú. Las Semblanzas. Trujillo: Ediciones de la Fundación Alfredo Pinillos Goicochea.t. I. 